\title{
TRABALHO PARA DEUS: PERCEPÇÕES DE PRAZER E SOFRIMENTO DAS FREIRAS LÍDERES RELIGIOSAS
}

\section{Work for God: perceptions of pleasure and suffering of religious leaders}

\author{
Luciano Zille Pereira ${ }^{1}$ \\ Christienne Lopes Silva ${ }^{2}$ \\ Jaqueline dos Santos Teles ${ }^{3}$
}

\begin{abstract}
RESUMO: Este estudo teve por objetivo analisar e descrever as vivências de prazer e sofrimento das freiras que exercem cargo de liderança em uma Congregação Católica localizada no estado de Minas Gerais. Metodologicamente, foi realizada uma pesquisa descritiva de abordagem qualitativa, por meio de estudo de caso, com a utilização de entrevistas como estratégia de coleta de dados. Foram entrevistadas nove freiras líderes religiosas com atuação na instituição pesquisada. Para análise dos dados utilizou-se a técnica de análise de conteúdo, estabelecendo a priori as categorias de análise: contexto do trabalho, custo humano do trabalho, vivências de prazer, vivências de sofrimento, danos relacionados ao trabalho e estratégias de regulação para lidar com o sofrimento. Concluiu-se que, para o grupo pesquisado, as vivências de prazer estão relacionadas diretamente à religiosidade que é a função norteadora da instituição para promover apoio social à comunidade, enquanto que o sofrimento provém de atividades, responsabilidades e exigências administrativas institucionais. Como estratégias de regulação utilizadas pelas freiras para lidar com o sofrimento, destacam-se as práticas religiosas, o apoio das colegas, a música, o cinema, o entretenimento social e as atividades físicas, que contribuem para minimizar os conflitos emocionais de cunho individual.
\end{abstract}

Palavras-Chaves: Psicodinâmica do trabalho. Prazer. Sofrimento. Líderes religiosas.

\begin{abstract}
This study aimed to analyze and describe the experiences of pleasure and suffering of nuns who hold leadership positions in a Catholic Congregation located in the state of Minas Gerais. Methodologically, a qualitative descriptive research was conducted through case study, using interviews as a data collection strategy. Nine religious leaders working in the institution surveyed were interviewed. For data analysis we used the technique of content analysis, establishing a priori the categories of analysis: work context, human cost of work, experiences of pleasure, experiences of suffering, work-related damage and regulatory strategies to deal with. the suffering. It was concluded that for the researched group, the experiences of pleasure are directly related to the religiosity that is the guiding function of the institution to promote social support to the community, while the suffering comes from activities, responsibilities and institutional administrative requirements. The regulatory strategies used by the nuns to deal with suffering include religious practices, peer support, music, cinema, social entertainment and physical activities, all of which contribute to minimizing individual emotional conflicts.
\end{abstract}

\footnotetext{
${ }^{1}$ Mestre e doutor em Administração pela Universidade Federal de Minas Gerais (1990, 2005), Graduação em Psicologia. E-mail: luciano.zille@unihorizonte.br

${ }^{2}$ Mestranda em Administração de Empresas no Centro Universitário UNIHORIZONTES (Bolsista FAPEMIG Fundação de Amparo à Pesquisa de Minas Gerais). Estudante de Direito no Centro Universitário Unihorizontes e graduada em Administração de Empresas pelo Centro Universitário UNA. E-mail: clopessilva21@hotmail.com ${ }^{3}$ Mestranda em Administração pelo Centro Universitário Unihorizontes. Especialista em Gestão de Pessoas pela Pontifícia Universidade Católica de Minas Gerais (PUC-MG). Graduação em Economia pelo Centro Universitário de Sete Lagoas. E-mail: jackteles@yahoo.com.br
} 
Keywords: Psychodynamics of work. Pleasure. Suffering. Religious leaders.

\section{INTRODUÇÃO}

No decorrer da evolução das civilizações, a religião católica se dispôs de forma organizacional, com objetivos, propostas e intenções para fornecer a religião para determinado grupo de pessoas (GUERRA, 2002). As igrejas e suas várias unidades se inserem na sociedade buscando disseminar seus ritos, símbolos, crenças e mitos por meio de atividades e preceitos divinos, caracterizando não apenas um lugar sagrado, mas também um ente organizado hierarquicamente (CARRANZA, 2005).

Nesse formato, destacam-se os trabalhos e as atividades das freiras líderes religiosas nas Congregações Católicas da pré-modernidade. A forma de organização do trabalho religioso da Igreja Católica passou por diversas mudanças ao longo dos anos, submetendo-se à transformação de seus paradigmas históricos, modificação de sua estrutura e novas definições na atuação de seus líderes religiosos (MENDES, 2006).

Segundo Gil-Monte (2016), em pesquisa realizada com indivíduos que atuam auxiliando pessoas carentes, tais como médicos, professores, policiais e religiosos, o grupo das freiras foi o que mais se destacou por sentirem-se sobrecarregadas do ponto de vista físico e psíquico. Deduz-se que as pessoas que interagem efetivamente em suas atividades em ajuda ao próximo estão submetidas às fortes exigências pessoais e das instituições às quais se vinculam (PEREIRA, 2016; ZILLE et al., 2018).

O estudo da saúde mental dos líderes religiosos, especificamente das freiras, tem se tornado cada vez mais relevante, visto que as atividades religiosas vão ao encontro de um ambiente competitivo, dinâmico e desafiador, caracterizado por dimensões formais e psicológicas (MENDES, 2006). As condições do ambiente de trabalho refletem diretamente na saúde física e mental de um trabalhador, e, segundo Spink (1996), esse ambiente pode ser empresarial, público ou do terceiro setor, incluindo, neste último, as entidades e associações filantrópicas e não governamentais, contemplando então, as atividades realizadas por freiras de uma Congregação Religiosa.

No decorrer do tempo, estudos das inter-relações de trabalho e saúde desencadearam o surgimento da disciplina denominada Psicopatologia do Trabalho (LIMA, 2007). Paul Sivadon (1907/1992) foi o precursor do termo Psicopatologia do Trabalho, alegando que as pessoas eram suscetíveis a desencadear distúrbios mentais decorrentes dos processos de trabalho. Como seguidor destaca-se Louis Le Guillant que investigava o surgimento e a extinção de doenças mentais ligadas diretamente ao meio social, não podendo compreender o indivíduo separado deste meio (LIMA, 2006). 
Em 1990 na França, tiveram início os estudos relacionados à Psicodinâmica do Trabalho, pelo psiquiatra e psicanalista Christophe Dejours. Essa abordagem científica investiga os mecanismos de defesa individuais e coletivos desenvolvidos pelo trabalhador para minimizar ou até mesmo neutralizar os impactos causadores de sofrimentos, distanciando assim, das doenças mentais (MENDES, 2007).

A psicodinâmica do trabalho proporciona fundamentos para que, dentro de um contexto de trabalho, seja possível o desenvolvimento de estudos entorno do prazer e sofrimento, bem como os mecanismos de defesa que os indivíduos utilizam para preservar a saúde mental, no contexto laboral (DEJOURS, 1993; FERREIRA; MENDES, 2006).

Ebert e Soboll (2009), afirmam que apesar da função religiosa ser vista como fonte de prazer, pode gerar também desgastes e frustrações, sendo ressaltada a importância de estudos nesta direção. Pesquisa realizada na base Scientific Periodicals Electronic Library - SPELL nos últimos cinco anos, com as palavras-chave "líderes religiosas" e "prazer e sofrimento", mostra a importância de se investigar vivências de prazer e sofrimento na percepção de líderes religiosas, o que torna o tema importante para a ampliação de estudos em relação a esta temática.

Diante do exposto, o presente estudo teve como objetivo analisar e descrever as vivências de prazer e sofrimento no trabalho vivenciado pelas freiras que atuam em funções de liderança em uma congregação católica na cidade de Belo Horizonte (MG).

\section{REFERENCIAL TEÓRICO}

\subsection{O sentido do trabalho na vida religiosa}

As atividades laborais permitem aos indivíduos a construção de sua própria realidade, além de gerar significância de pertencimento, promovendo a existência da espécie humana, configurando assim, um dos valores mais importantes na estrutura social, material e psicológica dos indivíduos na sociedade (NARDI, 2006; ROHM, 2015).

A congregação católica está enraizada em grande parte na formação da cultura e nos valores sociais da maioria dos indivíduos, principalmente das mulheres que buscam seguir o caminho da vida consagrada (JUNIOR; SALES, 2018). Para Guerra (2002), as instituições religiosas são consideradas como grandes organizações empresariais, uma vez que impõe os valores dogmáticos aos seus fiéis, solicitam doações para obras assistenciais e utilizam das ações administrativas com base em estruturar hierárquica formal.

As congregações católicas se organizam em forma de governo, com a existência de três poderes: o de ensinar, o de santificar e o de governar. Na primeira esfera, transmite o 
ensinamento da doutrina, visto como o poder mais importante da estrutura. Na esfera da santificação são aplicados os rituais oferecidos aos fiéis, tais como batizados, eucaristia, matrimônio entre outros. Na última esfera, a de governar, está às atribuições de ordem e tomadas de decisões administrativas nas congregações. Dentro dessa estrutura, moldam a forma de atuação e de limites de cada membro, assim, desde a entrada de um membro à congregação até a sua saída, este está submetido a um ordenamento ininterrupto (CASTRO, 2017).

A estrutura do governo católico conta com uma ramificação nos cinco continentes do mundo, todos padronizados hierarquicamente e eficaz no que diz respeito às normas $\mathrm{e}$ ensinamentos (EBC, 2013). Atualmente, a congregação católica possui 391 institutos religiosos, com aproximadamente 466.634 membros que exercem o sacerdócio, entre eles, o Papa que é a suprema autoridade; os cardeais que são responsáveis pelas funções administrativas do Vaticano; os bispos que têm o poder do sacramento e comandam as dioceses; os padres que são os ministros religiosos das Igrejas Católicas e as freiras que vivem a vida consagrada professando votos perpétuos à Igreja Católica e assumem compromissos de castidade, obediência e pobreza (STATISTICUM, 2016).

$\mathrm{O}$ voto de castidade refere-se à renúncia ao matrimônio, liberdade dos afetos emocionais e desejos corpóreos; a obediência é a inspiração do espírito na religiosidade, renunciando às próprias vontades e a pobreza refere-se à maturidade em utilizar e obter bens materiais apenas em prol da missão religiosa. Esses votos têm a finalidade de permitir a consagração religiosa e rompimento com as 'tentações humanas', quebrando possíveis amarras que impossibilitam de servir com amor e fraternidade ao próximo (DINIZ, 2017).

As freiras são preparadas para exercerem atividades pastorais, onde desenvolvem ações sociais, orientam e ajudam as pessoas necessitadas promovendo felicidade, conforto e alegria para os mais necessitados. No entanto, são responsáveis também por atividades administrativas, como a de dirigir ou gerenciar equipes, organizar documentos, tomar decisões e administrar escolas e hospitais (RODRIGUES; GOMES, 2013). Esse dualismo presente nas funções exercidas e todas as mudanças no ambiente religioso apresentam como uma fonte significativa para a construção pessoal da existência e do sentido da vida das religiosas (HERVIEU-LÉGER, 2008).

Segundo Silva (2004), tem-se exigido das líderes religiosas uma maior participação em relação ao trabalho, uma variabilidade de competências e atividades, jornadas de trabalho cada vez maiores, decisões cada vez mais práticas e rápidas para enfrentar a demanda e, por fim, uma maior eficácia nas tomadas de decisões. Assim, não basta ser apenas líder da 
congregação, é preciso ser também advogada, administradora, professora, enfermeira, psicóloga, política, assistente social, etc. (ANTUNES, 1999; HELOANI, 2003).

A vida consagrada experimentada pelas freiras líderes religiosas pode promover saúde e qualidade de vida, mas também pode causar sofrimento, levando ao adoecimento psíquico quando suas práticas escravizam ou confundem-se num contexto religioso de oferta (graças) e procura (fé); ou com um desejo de "sanar" as desilusões da vida por meio de crenças em uma proteção divina fácil e pronta. A responsabilização da própria freira acerca de seus desejos, necessidades e/ou fracassos, pode ocasionar, então, o consequente exercício de um trânsito religioso que, muitas vezes, ao invés de sanar angústias pode reforçar vazios, dúvidas existenciais, entre outros (KRINDGES, 2015).

\subsection{A psicodinâmica e as vivências de prazer e sofrimento no trabalho}

A Psicodinâmica do Trabalho foi construída inicialmente com fundamentação teórica da Psicopatologia, evoluindo para o estudo das relações dinâmicas do sofrimento psíquico do indivíduo, tendo as atividades do trabalho como o principal fator de contribuição para seu desenvolvimento. A expressão "Psicodinâmica do Trabalho" surgiu em 1990, na França, com o médico francês Christophe Dejours. Trata-se de uma abordagem científica autônoma, que tem objetivos, princípios, conceitos e métodos particulares para compreender a dinâmica do contexto do trabalho, focando nas vivências de prazer e de sofrimento, bem como as estratégias defensivas adotadas pelos trabalhadores (MENDES, 2006).

Segundo Dejours (1994), a racionalização do trabalho promovida pela inflexibilidade, controle rígido, ausência de liberdade criativa e espírito crítico, pode levar ao sofrimento do trabalhador. Nessa perspectiva, destacam-se como objetivo central os estudos da Psicodinâmica, envolvendo as questões de participação e as exigências das organizações em relação a atuação dos trabalhadores (MENDES, 2006).

A psicodinâmica apresenta uma inversão no modo de estudar a inter-relação do trabalho e saúde, ou seja, o ambiente de trabalho caracterizado por forças objetivas e subjetivas, sociais e econômicas, podem alterar a saúde e levar o trabalhador ao adoecimento (MENDES, 2007).

De um modo geral, essa abordagem tem como objetivo interferir no ambiente de trabalho, a fim de promover a saúde e evitar o adoecimento dos trabalhadores (LACKMAN; UCHIDA, 2003). As relações e formas de convivência no ambiente das organizações podem ser fruto de prazer e progresso do indivíduo, como também de sofrimento e adoecimento. $\mathrm{O}$ sofrimento pode ser caracterizado como "o espaço de luta que cobre o campo situado entre, de 
um lado, o 'bem-estar', e, de outro, a doença mental ou a loucura" (DEJOURS, 1996, p. 153). Já o prazer pode estar relacionado ao nível de execução de tarefas significativas julgadas pelo trabalhador.

O prazer ou o sofrimento emergem do contexto do trabalho do indivíduo (MENDES; MÜLLER, 2013), sendo considerado prazer às manifestações de gratificação, reconhecimento, valorização da atividade laboral e liberdade, já o sofrimento, é a transformação do ambiente em função de forças que remetem o desejo apenas da organização, dificultando as negociações, exigindo produção acima da capacidade, distanciando-se assim do bem-estar (MENDES, 2011).

Para Dejours (2008), o prazer é o conceito fundamental da psicodinâmica do trabalho, no entanto, não exclui o sofrimento, sendo então unidades inseparáveis. O trabalho tem como propósito o ganho de prazer, sua execução não se restringe apenas na obrigação de tarefa e atividades. O trabalho ultrapassa a realidade objetiva, e invade também o íntimo particular de cada indivíduo (MENDES, 1999).

Segundo Moraes (2013a), o sofrimento faz parte do processo de trabalho, uma vez que existe a possibilidade de fracasso, que faz o indivíduo sofrer, assim, os trabalhadores passam a utilizar e desenvolver mecanismos de defesa para mediar tal conflito e enfrentar o sofrimento. Para esse autor, não se pode eliminar o sofrimento do contexto de trabalho, mas é possível desenvolver mecanismos para favorecer a sua transformação em prazer.

Esses mecanismos, conhecidos também como estratégias de defesa ou regulação, para Dejours (2008c), "são recursos utilizados pelos trabalhadores, nas formas individuais e coletivas, para diminuir a carga de tensão no trabalho". Tais estratégias fornecem proteção psíquica para que os trabalhadores continuem a executar suas atividades de maneira menos penosa e infeliz (MORAES, 2013c).

Dessa forma, a psicodinâmica foi utilizada como referencial teórico para investigar a as vivencias de prazer e sofrimento no trabalho vivenciadas pelas freiras que atuam em funções de liderança em uma congregação católica.

\section{PERCURSO METODOLÓGICO}

Este estudo utilizou-se de abordagem descritivo-qualitativa visando analisar e descrever as vivências de prazer e sofrimento no trabalho vivenciado pelas freiras que atuam em funções de liderança em uma congregação católica na cidade de Belo Horizonte (MG).

Quanto aos procedimentos, a investigação foi desenvolvida por meio de um estudo de caso, permitindo reflexões e a compreensão de fenômenos, sejam eles individuais organizacionais ou sociais (RICHARDSON, 1999; YIN, 2001; GIL, 2008). 
A unidade de análise foi baseada nas vivências de prazer e sofrimento das freiras que atuam na Congregação Religiosa Filhas de Maria e a unidade de observação a Congregação Religiosa Filhas de Maria.

Os sujeitos da pesquisa foram nove líderes religiosas, de um total de vinte e uma, por exercerem as funções de liderança na congregação, caracterizadas como superioras provinciais, tesoureiras, diretoras, advogadas, economistas, assistentes sociais e coordenadoras administrativas.

Para a coleta dos dados foi utilizada a estratégia de entrevistas semiestruturadas e para acesso aos sujeitos da pesquisa, utilizou-se o critério de conveniência, por exercerem funções estratégicas na congregação (COLLIS; HUSSEY, 2005). A coleta de dados ocorreu de forma individual, no mês de março de 2019, utilizando-se de roteiro semiestruturado, com o intuito de desvelar as vivências subjetivas dessas religiosas, em relação às vivências de prazer e sofrimento. Foi garantido sigilo dos dados coletados a todas as entrevistadas, sendo que essas foram identificadas por códigos, iniciando em E1 até E9, para fins da análise dos dados.

O roteiro da entrevista contemplou, além de dados demográficos e ocupacionais, questões sobre contexto de trabalho, prazer e sofrimento, de modo a esclarecer as diferentes formas que estas experiências se apresentam, bem como os danos relacionados ao trabalho e as estratégias defensivas em relação às situações de sofrimento identificadas.

Todas as entrevistas foram gravadas, transcritas e analisadas à luz da técnica de análise de conteúdo categorial (BARDIN, 2011), técnica esta que permite obter, via procedimentos objetivos e ordenados a descrição do conteúdo das falas das entrevistadas. Segundo Bardin (2011), a análise de conteúdo pode ser realizada em três fases. A pré-análise é a fase em que se realiza a leitura flutuante dos relatos coletados nas entrevistas, buscando a aproximação e familiaridade das informações. Posteriormente, realiza-se a exploração do material, constituindo as categorias e subcategorias dos componentes e extraindo os conteúdos distintos e semelhantes. Na terceira fase procede-se ao tratamento e interpretações dos conteúdos, sintetizando e evidenciando as informações para análise, momento em que ocorre a análise reflexiva e crítica da base empírica obtida (BARDIN, 2011).

As categorias temáticas analisadas neste estudo tiveram como referência o Instrumento sobre Trabalho e Risco de Adoecimento (ITRA), desenvolvido e validado por Mendes (2007), consistindo em seis categorias: contexto do trabalho, custo humano do trabalho, vivências de prazer e sofrimento, danos relacionados ao trabalho, e estratégias de regulação.

\section{ANÁLISE E DISCUSSÃO DOS RESULTADOS}


A seguir procede-se a descrição e discussão dos resultados da pesquisa, consistindo na caracterização do perfil sócio demográfico e ocupacional das entrevistadas; descrição e discussão qualitativa dos dados relativos categorias e subcategorias que se mostraram relevantes. No quadro 1, apresenta-se o perfil sócio demográfico e ocupacional das nove líderes religiosas pesquisadas, que foram identificadas por meio de códigos que vão de E1 a E 9.

Quadro 1 - Perfil sócio demográfico e ocupacional

\begin{tabular}{|c|c|c|c|c|c|c|}
\hline Sujeitos & Idade & Escolaridade & Formação & Naturalidade & $\begin{array}{c}\text { Tempo de } \\
\text { serviço na } \\
\text { instituição }\end{array}$ & $\begin{array}{c}\text { Carga horária } \\
\text { semanal }\end{array}$ \\
\hline E1 & 60 & Superior Completo & História & Pará de Minas & 34 anos & Integral \\
\hline E2 & 40 & Superior Completo & Filosofia & Dores de Indaiá & 18 anos & 44 horas \\
\hline E3 & 79 & Superior Completo & Geografia & $\begin{array}{c}\text { Governador } \\
\text { Valadares }\end{array}$ & 22 anos & 30 horas \\
\hline E4 & 37 & Superior Completo & Psicologia & Capelinha & 15 anos & 44 horas \\
\hline E5 & 84 & Superior Completo & Pedagogia & $\begin{array}{c}\text { Conceição do } \\
\text { Mato Dentro }\end{array}$ & 62 anos & Integral \\
\hline E6 & 73 & Superior Completo & Pedagogia & Salinas & 52 anos & Integral \\
\hline E7 & 55 & Superior Completo & Pedagogia & $\begin{array}{c}\text { São Joao Del } \\
\text { Rey }\end{array}$ & 33 anos & 30 horas \\
\hline E8 & 81 & Superior Completo & $\begin{array}{c}\text { Letras e } \\
\text { Filosofia }\end{array}$ & Espera Feliz & 60 anos & Integral \\
\hline E9 & 45 & Superior Completo & $\begin{array}{c}\text { Serviço } \\
\text { Social }\end{array}$ & Betim & 15 anos & 44 horas \\
\hline
\end{tabular}

Fonte: Dados da pesquisa, 2019.

Destaca-se que três das pesquisadas possui o tempo de serviço na instituição superior a 50 anos, ainda, quatro trabalham em tempo integral, o que compreende a jornada de trabalho nas dependências da congregação e nas dependências da comunidade (serviço doméstico).

Como mostra o quadro 2, foram definidas, a priori, seis categorias, e identificadas em cada uma das subcategorias que se mostraram relevantes, comuns e marcantes nas falas das entrevistadas.

Quadro 2 - Categorias e subcategorias de análise

\begin{tabular}{|l|l|}
\hline \multicolumn{1}{|c|}{ Categorias de análise } & \multicolumn{1}{c|}{ Subcategorias } \\
\hline \multirow{3}{*}{ Contexto do trabalho } & - Significado do trabalho; \\
& - Planejamento e organização do trabalho; \\
& - Avaliação dos resultados. \\
\hline \multirow{2}{*}{ Custo humano do trabalho } & - Custo cognitivo; \\
& - Custo Afetivo. \\
\hline \multirow{2}{*}{ Vivências de prazer } & - Significado da instituição; \\
& - Identificação e realização com o trabalho; \\
& - Reconhecimento em relação ao trabalho; \\
& - Religiosidade. \\
\hline \multirow{2}{*}{ Vivências de sofrimento } & - Acúmulo de tarefas; \\
& - Sensação de fracasso; \\
& - Absorção pela instituição; \\
& - Realização de atividades administrativas. \\
\hline \multirow{2}{*}{ Danos relacionados ao trabalho } & - Danos físicos; \\
& - Danos psicológicos; \\
\hline
\end{tabular}




\begin{tabular}{|l|l|}
\hline & - Danos sociais. \\
\hline \multirow{3}{*}{ Estratégias de regulação } & - Apoio social de colegas de trabalho e familiares; \\
& - Atividade física e de lazer; \\
& - Prática religiosa. \\
- Ouvir Música
\end{tabular}

Fonte: Dados da pesquisa, 2019.

Nas próximas subseções será analisado o conteúdo das falas das entrevistadas, com base nas categorias e subcategorias que emergiram ao longo do estudo.

\subsection{Contexto do trabalho}

Esta dimensão representa as relações sócio profissionais e as condições de trabalho relativas à organização, e analisa-se os aspectos referentes ao significado do trabalho, planejamento e organização do trabalho e avaliação dos resultados.

As pesquisadas, ao relatarem sobre o 'significado do trabalho', confirmaram que o trabalho que desenvolvem é muito significativo para elas, pois gostam e se identificam com o que fazem e acreditam que o trabalho que executam tem um significado especial e importante para a sociedade e os mais necessitados, conforme pode ser observado no relato a seguir:

A minha escolha está fundamentada nas questões mais sociais, então eu escolhi ser religiosa e estar nesta congregação pelo trabalho missionário que ela faz, entendeu? Pois aqui ajudo as pessoas necessitadas, os pobres e me desdobro para a questão social (E4).

O trabalho, nesse contexto, representa uma identidade individual do sujeito ou o significado que se atribui a seu papel (GOUVEA, 2012). Conforme relato da entrevistada E1, sua identificação com o trabalho se dá também pelo desejo de realização espiritual e religiosa.

O meu desejo foi viver o evangelho do Nosso Senhor Jesus Cristo, e poder ajudar as pessoas conhecerem a sua história e lutar pelos seus direitos (E1).

A identificação com o trabalho, para Morin (2001), surge de um processo cognitivo resistente, que se baseia na comparação dele com a atividade e, também, nas percepções que o indivíduo possui sobre si mesmo.

No que se refere à subcategoria do 'planejamento e organização do trabalho' as pesquisadas relataram um ritmo intenso de trabalho e certo despreparo para realizar as atividades, demonstrando, assim, insatisfação e insegurança em relação às funções sob sua responsabilidade, o que é ilustrado pelos relatos a seguir. 
No meu caso tá frenético, né, porque eu preciso atender todos os setores, é claro que somos uma coordenação, mas assim a responsável sou eu (E1).

Nos primeiros anos de trabalho ocorre à incompetência, a gente tinha que dar aulas sem saber direito a matéria (E3).

Ainda, em relação ao planejamento e organização do trabalho, algumas das entrevistadas relataram que o planejamento para executar suas tarefas é desgastante, o que é possível confirmar diante do relato extraído das entrevistas.

Em uma semana vou a três cidades diferentes, então eu fico praticamente um dia aqui, dois lá, e isso me desgasta bastante, é muito corrido para fazer tudo que eu tenho pra fazer. O planejamento poderia ser mais bem realizado! (E4).

Segundo Batista (2000), o planejamento permite o desenvolvimento de um trabalho mais adequado e fluído, no que diz respeito à execução dos processos e identificação de possíveis falhas ou imprevistos.

Nesse contexto, os equipamentos utilizados no desenvolvimento das atividades são de extrema importância, e, neste quesito, a maioria das entrevistadas relatou que possuem um bom suporte tecnológico, além de uma estrutura física adequada, conforme relata a entrevista (E4).

Hoje temos meios técnicos como computador, que é imprescindível. Os equipamentos são apropriados, além do suporte técnico que recebemos. Tem que ter né! (E4).

Quanto à subcategoria 'avaliação dos resultados', percebe-se uma divergência nas falas das líderes religiosas. Nos relatos das entrevistadas E1, E3, E4, E5 e E8, as mesmas alegaram não ter avaliação dos resultados das atividades que realizam, no entanto, as entrevistadas E2, E6, E7 e E9 afirmaram serem avaliadas pela Coordenação Provincial. Os extratos a seguir, ilustram a situação mencionada.

Não existe avaliação não, elas pedem e a gente realiza (E5).

Temos uma avaliação anual com a coordenação provincial que é a Diretoria, e a cada quatro anos fazemos uma avaliação de tudo em uma Assembleia Eletiva (E9).

Segundo Silva (2019), a avaliação de desempenho focada em resultados, sendo essencialmente positiva para o bom desenvolvimento e resultados de uma instituição, além de ser um instrumento fundamental que contribui para a melhoria dos processos de trabalho, como também para a instituição como um todo.

\subsubsection{Custo humano do trabalho}


A categoria 'custo humano do trabalho' refere aos gastos físicos, cognitivos e afetivos que os trabalhadores gastam ao realizar suas atividades (FERREIRA, 2012). Diante do relato das entrevistadas, foram identificadas as subcategorias: custo cognitivo e custo afetivo.

O 'custo cognitivo' significa o dispêndio intelectual para aprender as atividades, resolver problemas e tomar decisões (MENDES, 2007). Nos relatos das entrevistadas E2 e E3 identifica-se que o maior desafio cognitivo enfrentado por essas entrevistadas está relacionado ao desenvolvimento de atividades que não haviam sido preparadas para realização, ou seja, a ocorrência de desafios intelectuais diários, o que pode ser observado pelos relatos apresentados a seguir.

Como a minha formação não é na área que eu exerço minhas atividades, esse é o meu maior desafio, né? Conjugar e conseguir desenvolver meu trabalho de forma sem deixar passar nada, nenhuma coisa importante, então eu me desdobro (E2).

Mandaram-me fazer coisas que eu não sabia, tinha que aprender sozinha, estudar sozinha, eu não sou formada para ser diretora ou ter que dar aulas (E3).

No que se refere ao 'custo afetivo', que é definido como o desgaste emocional na forma de reações afetivas e sentimentais que o trabalhador submete nos diversos contextos da organização (MENDES, 2007), percebe-se que o maior dispêndio das entrevistadas refere-se ao controle das emoções, disfarçando os sentimentos ao lidar com ordens contraditórias

Em muitos casos envolvemos emocionalmente, por isso temos que ficar sempre atentas e trabalharmos com o nosso emocional para não ficarmos pra baixo, tristes ... (E1).

. O relato apresentado está em consonância com os estudos de Gil-Monte (2016), que afirma, que os indivíduos que trabalham em favor das comunidades carentes e ajuda ao próximo são mais propensos a se envolver emocionalmente, além de se cobrar mais e sofrer internamente.

\subsubsection{Vivências de prazer}

As vivências de prazer estão relacionadas com as experiências de gratificação, valorização e reconhecimento do trabalhador dentro de uma determinada organização. Ligamse aos sentimentos de liberdade, realização, aceitação, gratificação e orgulho (FERREIRA; MENDES, 2003). 
Identifica-se como as principais vivências de prazer das líderes religiosas, o significado da instituição, a identificação e realização com o trabalho, o reconhecimento em relação ao trabalho e a religiosidade, que foram as subcategorias que emergiram desta categoria de vivências de prazer.

Na subcategoria 'significado da instituição', a maioria das entrevistadas afirmou que têm a instituição como uma família. Algumas relataram também que a instituição é a bússola norteadora que guiam e possibilitam a realização das atividades pastorais. Os relatos a seguir apresentados elucidam essa situação:

A instituição é o meu guia, meu norte. A instituição é o que assegura a nossa possibilidade de trabalho (E5).

A instituição é o meu lar, minha família, mas tem muitas tarefas e obrigações (E6).

Segundo Castro, 2017 o sentimento de pertença e segurança, garante, de certa forma, a proteção emocional que a vida em comunidade proporciona aos indivíduos. Contribui para evita a instabilidade emocional, considerando as situações de incertezas e insegurança quanto ao trabalho e moradia.

Com relação à subcategoria 'identificação e realização com o trabalho', grande parte das entrevistadas aponta estar motivada para realizar suas atividades e que sentem prazer quanto superam obstáculos e atingem os resultados. No entanto, algumas religiosas relataram que a motivação não está tão alta como antes, que não se sentem tão capazes de realizar as atividades administrativas, o que pode ser observado nos relatos a seguir.

Fico satisfeita quando resolvo uma situação difícil, quando resolvo algo do jeito que havia planejado, me sinto muito realizada profissionalmente (E7).

Eu sinto alegria para trabalhar, mas o peso do trabalho está muito elevado, eu não respondo mais como antes [...] tenho 79 anos e a motivação acompanha a idade [...] (E3).

A realização de um trabalho pode proporcionar ao indivíduo um sentimento capaz de lidar com situações adversas, funcionando como uma proteção aos sentimentos relacionados à frustração e ao sofrimento (SCHUTZ, 2018).

Apesar das entrevistadas demonstrarem, por meio de suas falas, as vivências de prazer relacionadas à satisfação e orgulho de exercerem as atividades profissionais, identifica-se nos relatos das líderes religiosas que a motivação parte apenas da execução de atividades pastorais/religiosas e não administrativas, ou seja, atividades sociais e de ajuda ao próximo.

Esses aspectos podem ser observados com os depoimentos apresentados a seguir: 
[...] ficar presa no escritório, sem tempo para sair e ver pessoas que precisam de ajuda é um sacrifício, gera muita insatisfação [...] (E8).

A satisfação está apenas no trabalho pastoral e não no administrativo. Me estressa essas questões burocráticas, não sinto satisfação (E9).

Quanto à subcategoria 'reconhecimento em relação ao trabalho', as entrevistadas, de forma geral, certificaram ser reconhecidas e valorizadas nas atividades que exercem, compartilhando de prazer este retorno da instituição, como também das pessoas que são atendidas. O relato obtido aponta nessa direção.

Sinto-me muito reconhecida, não só pela instituição e pelas irmãs, mas também pelas pessoas que eu já trabalhei ajudando (E1).

No tocante à subcategoria 'religiosidade', os relatos das entrevistadas mostraram-se relevantes. Afirma dedicar amor pela vida religiosa e sentir orgulho e satisfação em exercer atividades relacionadas à ajuda ao próximo. No entanto, no dia a dia, é exigida a realização de atividades administrativas, excessivamente burocráticas, o que desmotiva. Esses aspectos podem ser observados nos depoimentos a seguir:

Não estou tão motivada, já quis sair várias vezes, já pedi por escrito, eu não me formei pra escrever, minha profissão é ser religiosa (E8).

Vim buscar meu desenvolvimento religioso, e não ser diretora de uma escola (E9).

Segundo Freud (1980a), o indivíduo é instigado pelo desejo e busca de satisfação em relação aos seus objetivos, vontades e prazer. Assim, o prazer incorpora o jogo entre o desejo, o abandono e a recompensa (MENDES; MULLER, 2013). No campo psíquico, o prazer faz com que o indivíduo se adapte a situações inquietantes sem se abalar, podendo resultar também no equilíbrio do ser humano, tanto no plano físico como psíquico (TOLEDO; GUERRA, 2009).

\subsubsection{Vivências de sofrimento}

Segundo Dejours (2012a), o sofrimento é visto como uma espécie de drama que começa quando o trabalhador lida com situações contraditórias ou conflitantes. Pode ser gerado também quando o trabalhador não consegue realizar suas atividades, quando faltam informações e reconhecimento na execução das tarefas. 
Os depoimentos das entrevistadas revelaram que as principais vivências de sofrimento no trabalho estão relacionadas ao acúmulo de tarefas, sensação de fracasso, absorção pela instituição e realização de atividades administrativas.

Na subcategoria 'acúmulo de tarefas', as entrevistadas relataram que executam muitas atividades ao mesmo tempo, em pouco espaço de tempo e que se sentem esgotadas por não terem outra pessoa para dividir as responsabilidades e ajudá-las. É possível identificar também o despreparo das profissionais em realizar determinadas atividades administrativas. Os relatos a seguir ilustram esta situação.

No trabalho me sinto esgotada, tem muita coisa para fazer e pouco tempo para descanso, levo trabalho pra casa, trabalhamos 24 horas por dia (E9).

Existem muitas tarefas e pouco preparo técnico para que eu possa executálas (E7).

Nesse contexto, Mendes (2007) afirma que, quando um indivíduo em seu trabalho não consegue tempo e espaço para realizar as atividades e equilibrar seus desejos com os da organização, surgem às vivências de sofrimento. O sofrimento se caracteriza como sensação de medo, angústia, insegurança, esgotamento físico e psicológico, gerando contradições das reais necessidades e desejos dos trabalhadores (DEJOURS, 2001).

Quanto à subcategoria 'sensação de fracasso', percebe-se nas falas das líderes religiosas que o que mais gera frustração e sentimento de incapacidade no trabalho é a realização de atividades para as quais não foram preparadas profissionalmente e intelectualmente, o que pode ser observado nos relatos a seguir:

Os desafios e as dificuldades para realizar atividades para as quais não fui preparada me dá angústia, tristeza e sensação de fracasso (E7).

Quando eu percebo que deveria ter me preparado melhor deveria ter feito uma especialização para exercer aquela atividade, mas tinha que dar conta do trabalho e não me sobrava tempo para estudar (E8).

Depreende-se desses relatos, sentimentos como fracasso, angústia, tristeza e impotência que consequentemente gera desgaste emocional e sobrecarga profissional. Para Mendes (2007a), o sofrimento vivido no contexto de trabalho gera riscos de adoecimento e esgotamento para o trabalhador.

Outra subcategoria identificada nos relatos das entrevistadas foi a 'absorção pela instituição'. Para as entrevistadas, mesmo com os esforços desempenhados por anos na instituição, a exigência e demanda de atividades não diminuem. Para algumas entrevistadas, 
chegou a hora de um descanso merecido, uma aposentadoria, devido à idade e ao tempo de trabalho na instituição. Esses aspectos podem ser confirmados nas falas a seguir relatadas:

Chegou a minha hora, eu estou negociando com a instituição para que entenda que está na hora de eu parar, mas enquanto eles vêm um pouquinho de sangue, vão deixando a gente (E3).

Depois de cada turno eu sinto cansada, acho que é por causa da idade (E5).

Esses relatos permitiram observar que a sobrecarga das atividades, a exigência institucional pelo trabalho e a extensa jornada geram esgotamento, desgaste emocional e sofrimento.

Em relação à subcategoria 'realização de atividades administrativas', percebe-se que a frustração é da maioria das entrevistadas. O fato de a instituição religiosa exigir o exercício de atividades voltadas para a gestão administrativa, financeira e escolar, desmotiva e gera grande insegurança para as líderes religiosas, conforme é possível perceber nos depoimentos a seguir:

Eu já fui tesoureira sem saber nada, fazia tudo errado, tive que aprender na marra. Essas atividades administrativas são complicadas e ainda quando não há ninguém para ensinar (E3).

As atividades administrativas que temos que exercer geram bastante desafios e complexidades, muitas vezes não fomos preparadas para exercer essas atividades (E5).

Diante desses relatos, percebe-se que existe um conflito entre a prática de atividades religiosas e administrativas exigidas das líderes religiosas, gerando grande insatisfação e sofrimento.

\subsubsection{Danos relacionados ao trabalho}

Os danos relacionados ao trabalho são compostos por três fatores: danos físicos, que se referem aos distúrbios biológicos, relacionados ao desgaste corporal; danos psicológicos, que estão ligados aos sentimentos negativos em relação a si mesmo e à vida; e os danos sociais, que remete ao isolamento, dificuldades familiares e sociais dos trabalhadores (MENDES, 2007). Diante dos relatos obtidos, identifica-se a subcategoria relacionada aos 'danos psicológicos'. Para as líderes religiosas, o fato de executar tarefas para as quais não estão capacitadas psicologicamente, desencadeia sentimentos como sensação de vazio, abandono, solidão, tristeza e sentimentos de desamparo.

Entre as nove entrevistadas, cinco afirmaram sentir dúvidas sobre a capacidade de realizar as tarefas devido ao despreparo psicológico que se encontram. 
Eu sinto um pouco de despreparo psicológico para a função que realizo hoje, são muitas responsabilidades (E7).

Eu sempre me sinto despreparada para fazer os trabalhos e também sinto falta de uma pessoa que eu possa discutir o trabalho, não tem ninguém disposto a dividir comigo, a me ajudar, não tenho uma parceira, sinto abandonada, desamparada (E8).

Segundo Silva (2004), a falta de apoio aos líderes religiosos é presente nas instituições, o líder está completamente desamparado, o que contribui para desenvolver sentimentos de tristeza e solidão, como relata a entrevistada (E4).

Às vezes eu me sinto muito triste e sozinha com o meu trabalho, agora que eu consegui fazer uma equipe, mas acaba sempre que é você sozinha, entendeu? (E4).

Para Heloani (2003), as congregações religiosas da pré-modernidade vêm exigindo muito dos líderes religiosos, desde a variabilidade de competências e atividades, até as jornadas de trabalho cada vez mais longas e intensas. Atualmente, um líder religioso desempenha várias funções além da sua missão religiosa (SILVA, 2004), e isto é visto claramente na fala da entrevistada (E9), ao afirmar que não tem desejo de atuar administrativamente e sim, dedicar-se à religiosidade.

Eu acho que vem muito dessa questão de despreparo, assim, porque nós na maioria das vezes viemos com um desejo para vida religiosa e às vezes temos que atender outras solicitações e então é realmente, a questão não tá totalmente naquela função (E9).

As transformações dos contextos do trabalho e religioso exigem dessas líderes várias habilidades e atividades profissionais, construindo uma vida consagrada de duplos sentidos, em torno da religiosidade e da administração (SILVA, 2004).

\subsubsection{Estratégias de regulação}

As estratégias de regulação implicam em uma ação consciente do indivíduo para lidar com o sofrimento, como, por exemplo, ir à igreja. Esta ação pode refletir o mecanismo inconsciente chamado de "deslocamento"; ou seja, a transferência de emoção associada a um objeto (organização) para outro (igreja), de modo que tal sentimento possa ser experimentado sem nenhum risco (SILVA, 2004).

Diante dos relatos das entrevistadas, identificou-se como subcategorias das estratégias defensivas para lidar com o sofrimento no trabalho o apoio social de colegas e familiares, atividade física e de lazer, e a prática religiosa. 
Concernente à subcategoria 'apoio de colegas e familiares', as entrevistadas afirmaram que, quando estão enfrentando situações complicadas nas atividades laborais o encontro com amigos e familiares ajuda a esquecer estas preocupações. Destaca-se a importância do apoio dos colegas para o enfrentamento das tensões do trabalho, principalmente de colegas que não estão envolvidos nas atividades laborais das entrevistadas, como pode ser observado nos relatos a seguir:

Quando chega o momento que não estou aguentando mais, eu gosto de sair com os meus amigos, conversas, bater papo [...] (E4).

[...] eu procuro uma pessoa que às vezes nem está no nosso assunto, que não é da congregação e você pode conversar e espairecer (E8).

Em relação às 'atividades físicas e de lazer', as entrevistadas apontaram que é uma maneira de se desligarem dos problemas relacionados ao trabalho, como mostra os depoimentos a seguir apresentados. Para as entrevistadas essa estratégia se faz necessário, principalmente, quando estão num elevado grau de exaustão.

Eu faço Pilates, caminho e durmo. Adoro sair para comer uma pizza, cair na piscina (E1).

[...] agora a válvula de escape para o descanso me agrada ir ao cinema, ler algum livro, viajar [...] (E8).

A subcategoria 'prática religiosa' é outra estratégia de regulação usada pelas pesquisadas. Quatro das entrevistadas afirmaram usar a oração e a fé em Deus para lidar com as pressões diárias do seu trabalho.

Ainda que o trabalho proporcione prazer aos trabalhadores, as estratégias defensivas são necessárias e importantes à saúde na busca de equilibro psíquico (MENDES, 2007a).

Por fim, outra estratégia defensiva identificada nos relatos das entrevistadas foi a subcategoria 'ouvir música'. Para as pesquisadas, essa atividade contribui significativamente para fortalecer e evitar os desgastes emocionais que podem surgir nas relações de trabalho.

A utilização das estratégias de regulação ajuda o indivíduo a enfrentar as dificuldades e auxiliam nas situações de sofrimento, favorecendo assim, o equilibro emocional. Percebe-se que a maior parte das estratégias utilizadas pelas entrevistadas é de cunho individual, não impactando o contexto da instituição, ou seja, não favorece ou transforma as condições precárias do trabalho as quais são submetidas (MORRONE, 2001).

\section{Considerações Finais}

O estudo buscou descrever e analisar o prazer e o sofrimento vivenciados pelas freiras de uma congregação católica situada no estado de Minas Gerais. As líderes religiosas 
desenvolvem suas atividades na Congregação Religiosa Filhas de Maria, localizada na cidade de Belo Horizonte (MG).

A base teórica de análise teve como referência a psicodinâmica do trabalho e, em termos metodológicos, utilizou-se de abordagem descritivo-qualitativa, por meio de estudo de caso. A coleta dos dados foi realizada com base em entrevistas semiestruturada e, posteriormente, os dados foram submetidos à análise de conteúdo, baseado em seis categorias, fundamentada no Instrumento Trabalho e Risco de Adoecimento (ITRA). As categorias analisadas foram: contexto do trabalho, custo humano do trabalho, vivências de prazer, vivências de sofrimento, danos relacionados ao trabalho e estratégias de regulação. Com base no conteúdo das entrevistas, emergiram 18 subcategorias as quais foram objeto de análise.

$\mathrm{Na}$ categoria 'contexto do trabalho', as religiosas relataram que identificam com o trabalho que realizam, de forma mais específica em relação às práticas religiosas, que tem uma representatividade significativa junto à sociedade, estando, portanto, associado ao desejo de realização espiritual e religiosa. Em relação às atividades administrativas, de certa forma, não se identificam e não se consideram preparadas para executá-las. Dessa forma, esse constitui um dos maiores desafios do trabalho dessas religiosas, além de ter que se adaptarem e prever determinadas ocorrências administrativas no âmbito da instituição. Outro aspecto que pode estar relacionado com as práticas administrativas é a idade cronológica avançada das religiosas, aproximadamente $70 \%$ delas estão com idades variando entre 55 a 81 anos.

As percepções de prazer estão relacionadas diretamente à religiosidade e à função norteadora da instituição em promover apoio social para a comunidade. As entrevistadas consideram a instituição como sua família, e se sentem motivadas para realizarem as atividades religiosas e sociais, sentindo-se valorizadas e orgulhosas no desempenho deste trabalho. Já em relação às vivências de sofrimento que causam angústia, solidão e tristeza, as líderes religiosas apontam a realização de vários trabalhos ao mesmo tempo (administrativos, religiosos e sociais), a necessidade de melhor organização das equipes de trabalho para compartilharem as responsabilidades e as exigências institucionais elevadas, sobretudo para as religiosas mais velhas. Dessa forma, no que tange às vivências de sofrimento, fica claro que o acúmulo de tarefas, entre elas as administrativas, e a falta de preparo para realizá-las, resulta em esgotamento físico e psíquico, além de apontar para um alto risco de adoecimento mental.

Ao se referirem aos danos relacionados ao trabalho, algumas entrevistadas apontaram sentir um vazio, certo abandono, solidão e despreparo para realizar suas atribuições diárias, principalmente, aquelas de cunho administrativo, envolvendo os processos de trabalho e as atividades relacionadas à gestão dos órgãos que compõem a instituição. 
Por fim, as entrevistadas abordaram as estratégias de regulação, sendo que, diante dos relatos, percebeu-se que as religiosas utilizam estratégias individuais relacionadas ao lazer e coletivas para lidar com a sobrecarga emocional, tais como o apoio das colegas, música, cinema, entretenimento social e atividades físicas e práticas religiosas.

Diante do contexto analisado, foi possível observar que as vivências de sofrimento se apresentam, de certa forma, intensas na percepção das religiosas, no entanto, são compensadas pela humildade, generosidade, amor ao próximo e a obediência, que caracterizam e moldam a forma de como veem o mundo e como se relacionam com ele, sempre prezando pelo bem-estar do próximo, com ações de religiosidade e apoio social aos necessitados.

O estudo contribuiu de forma importante para ampliar as pesquisas relacionadas psicodinâmica do trabalho, considerando um lócus, que de certa forma, pode ser considerado ainda pouco explorado pelas pesquisas científicas. Essa iniciativa, de forma adicional, contribui no plano acadêmico para incentivar pesquisas nessa direção, de forma a aprofundar os conhecimentos científicos relacionados às vivências de prazer e sofrimento no contexto ocupacional, na percepção das líderes religiosos, espaço este, ainda cercado de muitas indagações. Outra contribuição a ser destaca se dá no plano metodológico, transportando a abordagem quantitativa preconizada pelo INTRA em abordagem qualitativa, em que as questões que compõem o instrumento foram transformadas em perguntas que compuserem o roteiro semiestruturado para a realização das entrevistas com as nove líderes religiosas pesquisadas.

Contribuiu também de forma importante no plano institucional, à medida que discutiu aspectos relacionados ao trabalho em si, sobretudo diante das transformações que vem ocorrendo nesta área e, que de certa forma, está impactando os diversos setores das organizações, entre eles a instituição religiosa. Com base nos resultados obtidos, foi possível identificar vivências de sofrimento por que vem passando as líderes religiosas pesquisadas. De posse desses dados, a instituição poderá rever as políticas e as estratégias de organização do trabalho, de forma a transformar o trabalho considerado 'penoso' em um trabalho 'prazeroso', sobretudo, levando em consideração o perfil dos indivíduos envolvidos na sua execução. Dessa forma, contribui de forma importante incentivando reflexões sobre a necessidade de mudanças quanto às práticas de gestão de pessoas e a reestruturação do trabalho visando o efetivo prazer destas "profissionais religiosas", elevando assim, o nível da qualidade de vida no trabalho.

Destaca-se também a sua contribuição no plano social, à medida que permitiu evidenciar as vivencias de prazer das líderes religiosas, tanto em termos de apoio religioso, 
como apoio social mais amplo no âmbito da sociedade, sobretudo para os mais necessitados, onde reafirmam a constante busca do trabalho em prol do ser humano tendo como base os ensinamentos de Jesus Cristo.

Esta pesquisa possui suas limitações, destacando-se o fato de a mesma ter sido realizada em uma única instituição religiosa. Nessa direção, sugere-se a continuidade de estudos, tendo como referência a Psicodinâmica do Trabalho, envolvendo diferentes congregações religiosas.

\section{REFERÊNCIAS}

BARDIN, L. Análise de conteúdo. 6. ed. Lisboa: Edições 70, 2006.

BAPTISTA, M. V. Planejamento social: intencionalidade e instrumentação. São Paulo: Veras Editora; Lisboa: CPIHTS, 2000.

CARRANZA, B. Religião e espiritualidade: um olhar sociológico. In: AMATUZI, M. M. (Org.), Psicologia e espiritualidade. São Paulo: Paulus, 2005.

COLLIS, J.; HUSSEY. R. Pesquisa em administração. São Paulo: Bookman, 2005.

DASHTIPOUR, P.; VIDAILLET, B. Work as affective experience: The contribution of Christophe Dejours' 'psychodynamics of work'. Organization, v. 24, n. 1, p. 18-35, 2017.

DEJOURS, C. Sofrimento e prazer no trabalho: a abordagem pela psicopatologia do trabalho. In: LANCMAN, S.; SZNELWAR, L. I. (Org.). Christophe Dejours: da psicopatologia à psicodinâmica do trabalho. Rio de Janeiro: Fiocruz; Brasília: Paralelo 15, 2008 a.

DEJOURS, C. Uma nova visão do sofrimento humano nas organizações. In: CHANLAT, J. F. O indivíduo na organização: dimensões esquecidas. 2. ed. São Paulo: Atlas, 1993.

DEJOURS, C. A loucura do trabalho: estudo de psicopatologia do trabalho. São Paulo: Cortez, 1998.

DE COMUNICAÇÃO, EBC-Empresa Brasil. Hierarquia da Igreja Católica. 2013. Disponível em: <http://www.ebc.com.br/noticias/internacional/2013/03/entenda-a-hierarquiade-governo-da-igreja-catolica> Acesso em: 15 Mar de 2019.

EBERT, C.; SOBOLL, L. A. P. O trabalho pastoral numa análise da Psicodinâmica do Trabalho. Aletheia, n. 30, p. 197-212, 2009.

FERREIRA, M. C. Qualidade de vida no trabalho: uma abordagem centrada no olhar dos trabalhadores. São Paulo: Paralelo 15, 2012.

FERREIRA, M. C.; MENDES, A. M. Trabalho e riscos de adoecimento: o caso dos auditores-fiscais da Previdência Social Brasileira. Brasília: Ler, Pensar, Agir. 2003.

GIL, A. C. Métodos e técnicas de pesquisa social. 6. ed. Editora Atlas SA, 2008. 
GIL-MONTE, P. R. Bateria UNIPSICO: propriedades psicométricas das escalas que avaliam os fatores de demanda psicossocial. Arquivos de prevenção de riscos ocupacionais, v. 19, n. 2, p. 86-94, 2016.

GUERRA, Y. A instrumentalidade do serviço social. Cortez Editora, 2002.

KUBO, S. H.; GOUVÊA, M. A. Análise dos fatores associados ao significado do trabalho. Revista de Administração, v. 47, n. 4, p. 540-554, 2012.

HELOANI, J. R. Gestão e organização no capitalismo globalizado - história da manipulação psicológica no mundo do trabalho. São Paulo: Atlas, 2003.

HELOANI, J. R. Saúde mental no trabalho: algumas reflexões. In: MENDES, A. M. (Org.). Trabalho e saúde: o sujeito entre servidão e emancipação. Curitiba: Juruá, 2011.

HERVIEU-LÉGER, D. Producciones religiosas de la modernidad. Modernidad, religión y memoria. Buenos Aires: Colihue, 2008.

HERVIEU-LÉGER, D. O peregrino e o convertido: a religião em movimento. Petrópolis: Vozes, 2008.

LANCMAN, S.; UCHIDA, S. Trabalho e subjetividade: o olhar da psicodinâmica do trabalho. Cadernos de Psicologia Social do Trabalho, São Paulo, v. 6, p. 79-90, dez. 2003.

MENDES, A. M. B. Valores e vivências de prazer-sofrimento no contexto organizacional. Brasília: Universidade de Brasília, 1999.

MENDES, A. M.; SILVA, R. R. Prazer e sofrimento no trabalho dos líderes religiosos numa organização protestante neopentecostal e noutra tradicional. Psico-USF, Itatiba, v. 11, n. 1, p. 103-112, jan/jun. 2006.

MENDES, A. M. Da Psicodinâmica à Psicopatologia do trabalho. In: MENDES, A. M. (Org.). Psicodinâmica do trabalho: teoria, método e pesquisa. São Paulo: Casa do Psicólogo, 2007a.

MENDES, A. M. Prazer, Reconhecimento e transformação do sofrimento no trabalho. In: MENDES, A. M. (Org.). Trabalho e saúde: o sujeito entre servidão e emancipação. Curitiba: Juruá, 2011. 13-25 p.

MENDES, A. M.; MULLER, T.C. Prazer no trabalho. In: VIEIRA, F. O; MENDES, A. M; MERLO, A. R.C. (Orgs.). Dicionário crítico de gestão e psicodinâmica do trabalho. Curitiba: Juruá, 2013. 289-292 p.

MENDES, A. M.; LIMA, S. C.C. Diálogos em psicodinâmica do trabalho. Brasília: Paralelo, v. 15, 2007.

MORAES. R. D. Estratégias de enfrentamento do sofrimento e conquista do prazer no trabalho. In: MERLO, A. R. C.; MENDES, A. M.; MORAES, R. D. O sujeito no trabalho: entre a saúde e a patologia. Curitiba: Juruá, 2013c. 289-292 p.

MORIN, E. Os sentidos do trabalho. Revista de Administração de Empresas. São Paulo, v. 41, n. 3, p. 8-19, jul./set., 2001. 
MORRONE, C. F. Só para não ficar desempregado resinificando o sofrimento psíquico no trabalho: um estudo com trabalhadores em atividades informais. 2001. 141f. Dissertação (Mestrado em Psicologia). Universidade de Brasília, Brasília. 2001.

NARDI, H. C. Ética, trabalho e subjetividade: trajetórias de vida no contexto das transformações do capitalismo contemporâneo. Porto Alegre: UFRGS, 2006.

PEREIRA, J. A. de S. Vivências de prazer e sofrimento na atividade gerencial em empresa estratégica: o impacto dos valores organizacionais. 2003. 165 f. Dissertação (Mestrado em Psicologia). Instituto de Psicologia. Universidade de Brasília, 2003.

RICHARDSON, M. Fundamentos da metodologia cientifica. São Paulo, 1999.

SCHUTZ, A. A construção significativa do mundo social: Uma introdução à sociologia compreensiva. Editora Vozes, 2018.

SPINK, P. A organização como fenômeno psicossocial: notas para uma redefinição da psicologia organizacional e do trabalho. Revista Psicologia e Sociedade, 8(1), 174-192, 1996.

TOLEDO, D. A. C.; GUERRA, A. C. Um estudo sobre o prazer no trabalho: pensando dimensões de análise. Encontro da Associação de Pós-Graduação e Pesquisa em Gestão, v. 33, p. 200, 2009.

ECCLESIAE, Annuarium Statisticum: annuarium statisticum ecclesiae. Rome: Vatican Secretary of State, 1987. Disponível em: <https://www.vaticannews.va/pt/vaticano/news/2018-06/anuario-pontificio-2018-annuariumstatisticum-ecclesiae.html > Acesso em 28 Fev de 2019.

YIN, R. K. Estudo de caso. 2. ed. São Paulo: Sage, 2001.

ZILLE, L. P. et al. Occupational stress: a study in a brazilian public university hospital. In: ISSWOV INTERNATIONAL SOCIETY - WORK \& ORGANIZATIONAL VALUES, 2018, Trieste. Anais... Bruxelas: ISSWOV, 2018. 